\title{
Interrogation in Nigerian Police-suspect Discourse
}

\author{
Farinde, Raifu Olanrewaju \\ Department of English and Literary Studies, Federal University Oye-Ekiti, Nigeria \\ Oyedokun-Alli, Wasiu Ademola \\ Department of English and Literary Studies, Federal University Oye-Ekiti, Nigeria \\ Iroegbu Obinna \\ Department of English and Literary Studies, Federal University Oye-Ekiti, Nigeria
}

\begin{abstract}
Police-suspect interrogation is a peculiar discourse genre where there is interplay of power and dominance. This study examines the process by which linguistic coercion by the police is being actualized. The data for the study were interrogations between the police and some suspects that were selected within Ondo and Ekiti State Police Commands. The towns were purposively chosen based on their geographical spread across the Ondo Area Command as well as their population and commercial advantages. The data gathered were transcribed and analysed using Gibbons' Forensic Questioning model. Since police-suspect interaction is based on questions and answers, questions in police-suspect interaction were classified according to the degree of power embedded in them. The result indicated that assault, abduction, affray and robbery were the common themes in Police-Suspect Discourse. The findings of the study reveal that in Police-Suspect Discourse there are such questions as declarative, choice, restricted and non-restricted WH-questions, special formulas and projected questions. The study further reveals that the questioning strategies of the police afford them the opportunity of controlling the interrogation. The more frequently the police use questions, the more they are coercive.
\end{abstract}

Index Terms — asymmetrical power, interrogation, linguistic coercion, police-suspect interaction, questioning

\section{INTRODUCTION}

The interrogation that was recorded for this study was conducted at the Nigeria police Station, Yaba-Ondo, the Nigeria police Station Iyin-Ekiti and the Nigeria police Station, Owo. In each of the Police Station visited, the recordings consist of the investigating police officers (IPO) some other police men and the suspects. In all the recordings, most of the conversations were between the investigating police officers and the accused persons. Hence, nearly all of the discourses occurring are essentially two-party talk, between the investigating police officer and the accused person. The investigating police officer is also one of the police officers but because he is in charge of the case in question, he is called the investigating police officer. He is knowledgeable in the law guiding the case in question, and thereby wielding more power on the suspect. The suspect is the person who has committed the offence of the case. Because of this, he is at the mercy of the investigating police officer who wields power over him.

Confessions have often been cited as the most powerful evidence in producing a guilty verdict. The techniques the police use in their interrogations have been said to be coercive and may elicit false confessions (Underwager \& Wakefield 1992; Leo 1996). The interrogation is eventually an asymmetrical type of dialogue, which denotes the fact that the goals and methods of argumentation used by the one side are quite different from those on the other side. The goal of the questioners is to get any kind of information out of the respondent that is needed for some purpose, like taking action to prevent harm or pursuing an investigation. The goal of the respondent is to pursue his/her own interests and goals, as he/she sees them, balancing them against the wider needs and interests of the community. It is up to him/her to decide whether his/her interests are best served by giving out information or by withholding it. He/she may decide to give out wrong information that will deceive his/her interrogator, or lead him/her in a wrong direction (Levy, 1999) as cited in Walton, 2003).

The questioner is usually a police officer. The respondent can be either a suspect or a witness. According to Walton (2003, p.1777), the respondent wants to conceal the information he possesses, but the questioner wants to reveal this information so that he can pass it on to his/her superiors who have a use for it. In this regard, there is generally a coercive element in interrogation.

Walton (2003, p. 1778) identifies four stages in interrogation which are:

- The formative stage

- The preparatory stage

- The argumentative stage 
- The closing stage.

The formative stage is that in which some trial or tribunal requires evidence to be collected. At this stage, the framework is set in place that will determine what kind of information is being sought, as relevant to the case. Also, the preparatory stage in which the questioner gets an idea of 'what to ask' and makes a list of the questions that are to be asked to the respondent. The argumentative stage is the actual dialogue sequence of questions and answers which are typically recorded in notebooks, or a video or audio tape recording. Lastly is the closing stage of the interrogation, which the session is concluded and the body of information that has been collected is assembled in some form. This is the prerogative of the questioner who feels that he/she has got the information needed.

According to Walton (2003, p. 1781), one factor that makes the interrogation distinct from the basic type of information-seeking dialogue is that of the freedom of the participants. In a normal information-seeking dialogue, it would be assumed that both parties are freely engaging in the dialogue and that one party is not the prisoner of the other. He further argues that it is a normative requirement of the simple kind of information-seeking dialogue that both parties should be free to ask questions or put forward arguments or opinions. Neither party should bring pressure to bear to try to prevent the other party from putting forward such arguments or opinions. In fact, bringing such pressure to bear, for example, by using threats would normally be considered fallacious in information-seeking dialogue. In the interrogation, however, the respondent's role is like that of a prisoner of the party who asks the questions. Thus, the interrogation is quite different from the normal kind of information-seeking dialogue.

Because police-suspect interrogation is based on question and answer adjacency pairs, this paper will limit itself to questioning in police-suspect discourse. In information-seeking dialogue we have a social relationship that permits a request for information but does not demand a response and an informational relationship in which the respondent has the information and the questioner does not. However, in police-suspect interrogation, the police interrogators have the right to demand a reply, and often assume that they already have the information that is to be supplied by the respondent. These atypical personal and information relationships have a significant impact on the nature of both questioning exchanges and the form of questions (Gibbons, 2008). This paper will examine this exemplified by the recorded policesuspect data.

\section{LITERATURE REVIEW}

As maintained earlier, police interrogation is a socio-discursive context where the relationship is highly asymmetrical. That is there is power differential in police suspect discourse. The type of power in this context is very obvious and glaring because of the institutional rules and procedures. This means that it is the regulation of the society that vests the police officer with Institutional power over the suspect and the accused. Thus, in this regard, the police officer determines the topic of the interrogation, asks questions, interrupts, challenges, accuses and gives direction. During interrogation, the aim of the police interrogator is to secure a confession from the suspect and due to this, he/she makes use of several strategies to enable the offender to confess his/her guilt.

To support this argument, Farinde (2010, p.255) identifies the following Act forms that police use to obtain confession from the suspects: Elicitation, Directive, Prompt, Evaluation, Accuse, Excuse and Reply/Informative. According to him, the Elicitation Act form is used by the police to information from the accused persons. The Directive act form is used in police-suspect discourse by the police to instil fear in the accused person. Also, the Prompt Act form entails the use of persuasion, threat and torture to force the accused person to confess having committed the crime he is alleged to have committed. The Accusation Act form is used by the police to catch the accused person off-guard, thereby making him to confess his crime unwittingly. The Evaluative Act form is used by the police to decide whether the accused person is speaking the truth or not. And finally, Reply/Informative is the major Act form used by the accused person. The accused person is always replying to the Elicitation and Prompt Act forms of the police.

All the above Act forms highlighted by Farinde (2010, p.255) can only be used during interrogation by the police interrogator. Therefore, they symbolize the power that the police have over the suspect. Elicitation Act form contains questions. Only the police can ask questions during police suspect interrogations, except the questions asked by the suspect to seek clarification of the interrogator's questions. This means that in this context, the police can be said to have power over the suspect. In some other contexts such as in a conversational setting, asking a question can be said to offer the floor to the questioned person and demonstrate the questioner's interest in the answer (Goody 1978, Fishman 1983). Since the prompt Act form entails threats and persuasion and this is used by the police, then the police are having power and control over the suspect.

Also, the Directive Act form, Accuse Act form, and Evaluative Act form are always used by the person occupying the higher position and therefore, they are entitled to use these Act forms. It indicates that there is an asymmetrical relationship between the police and the suspect. The police are always using their power and control to persuade the suspect to confess their crime. By using Directive Act form, a speaker proposes to exert control over the other conversational participants (Goodwin, p.1990). In institutional dyads (attorney-witness, teacher-student, physicianpatient), typically, the speaker who has the power to reward i.e. attorney, teacher, physician has asked the most questions and the imbalance in numbers has been dramatic (Dillon, p.1990). The above are just buttressing the fact that only the person that is superior such as the police interrogator-can give directive, reward, evaluate, accuse and even ask most questions. 
Farinde's (2010, p.255) is a detailed work that could be described to have done justice to the subject matter. The work also gives a standard structure to police-suspect discourse. However as salient and glaring as the concept of power relations is in police-suspect discourse, the work does not focused on this in the study. Also as preponderance as questioning is in police-suspect discourse, the work does not dwell much on this.

Speaking along the same vein and noting the goals the interrogation is meant to serve, Watson (2003, p.1778) maintains that since the suspect or the accused person is essentially reluctant to make a confession, the police interrogator must use tricky techniques to get results. First of all, the interrogator must appear to be friendly and cooperative, even sympathetic to the suspect. Second, the questioner must be very patient and give plenty of time for answer. Third, the interrogator must be methodical and go by a list of questions that have been previously prepared. Fourth, the interrogator must repeat questions that have not been answered yet. And fifth, and most important, the interrogation must go on for a long, indefinite period of time. The technique is to wear the suspect down, and to convey to him the idea that the tiresome interrogation will only be over when he yields the sought-after information. The methods above still lead credence to the fact that the police have power and control over the suspects and they can use several techniques to obtain a confession from the suspect. In police interrogation, the suspect is always trying as little information as possible, or certainly does not generally stand to gain by putting out lots of information, while the interrogator is always trying to prevent the suspect from concealing this information.

Watson's paper is a comprehensive work on the strategies that police use to obtain confession from the suspect. Just like Farinde's work, the paper did not show the asymmetrical power relationship existing between the police and the suspect. Also, questioning forms in police-suspect interrogation are not portrayed.

Hall's (2008) paper engages the language of police. He uses careful transcriptions of police questioning in New Wales to show how the function of various elements of police interrogations are realised in language, and also the considerable degree to which these functions are performed in a formulaic way, using set phrases and expressions. For example, Hall maintains that establishing motive is always manifesting in police speak. When a police interrogator asks a suspect, 'And what made you do it', he/she is specifically attempting to establish a 'motive'. Also according to Hall (2008), establishing knowledge on the part of a suspect may also be of high importance to police interrogator's attempt to build a case. Knowledge in this specialized sense refers to a suspect's awareness of details which are likely to be known only to the perpetrator of a crime and, importantly, are able to be confirmed as true by investigators. For this reason, when a suspect has made a confession, knowledge may be a factor in determining whether the confession is genuine.

Although Hall's paper dwells much on questioning, questioning forms are not addressed in the work. The work also concentrates on gradual building of knowledge to the neglect of power imbalances existing in police-suspect discourse.

Adegbite's (2013) work contributes to knowledge in the field of pragmatics by exemplifying the pragmatics concept of politeness, using fresh data from police-suspect interrogation in English as a Second Language (ESL) context. It provides insights into the use of language by Nigeria Police interrogators by exploring their politeness strategies in suspect interrogation. The study also shows that police-suspect interrogation as a discourse genre can be used to explicate the postulations of the Brown and Lenvinson's (1987) politeness model and that the model is adequate in elucidating the politeness pragmatics of institutional dyadic discourse of unequal participants, example of which is police-suspect interrogation. It also extends the frontiers of knowledge in language study via the application of pragmatic tools to the analysis of police interrogation texts.

Although Adegbite's work is a detailed study on police-suspect discourse, its focus is on application of politeness principle to the police-suspect discourse to the neglect of questioning forms that constitutes the major part of the discourse in this genre. It is to the credit of the study that the issue of power imbalances is also addressed.

Ajayi's (2016) work focuses on politeness and impoliteness strategies and power abuse in police-suspect interaction in Ibadan, Nigeria. Based on Brown and Levinson's Politeness theory, Culpeper's Impoliteness theory, Fairclough and Wodak's Principles of Critical Discourse Analysis, and making use of 35-hour audio-recording involving 66 police officers and 58 suspects at the State Criminal Investigation Department Headquarters, Iyaganku, Ibadan, Oyo State, Ajayi discovers that Investigating Police Officers employed bald on record without redress impoliteness, positive impoliteness, negative impoliteness, withhold politeness and mock politeness strategies to attack the faces of suspects, wield power over them, and violate their rights during interrogation. They employed negative and positive politeness strategies to minimise the attack on the faces of cooperative suspects. The suspects employed positive politeness strategies to appeal to the faces of the Investigating Police Officers. Ajayi affirms that the Investigating Police Officers dominated police-suspect interaction with (para)linguistic phenomena as question, paralanguage, interruptions, verbal abuse and verbal threat.

Ajayi's study is a very comprehensive work on police-suspect interaction. Yet, as detailed as the work is, it does not cover the questioning forms in police-suspect interaction. This present work will take care of all the shortcomings observed in all the reviewed studies. Specifically, this present work will ex-ray questioning forms as a strategy employed by Investigating Police Officers to dominate police-suspect interrogation. Also, the work will illustrate how power is unevenly distributed between police officers and suspects in favour of the former in police-suspect interrogation. 


\section{METHODOLOGY}

The data for the study were interrogations between the police and some suspects. They were selected within Ondo and Ekiti State Police Commands. The interrogation was recorded at the Nigeria police Station, Yaba-Ondo, the Nigeria police Station Iyin-Ekiti and the Nigeria police Station, Owo. The towns were purposively chosen based on their geographical spread across the Ondo and Ekiti Areas Command as well as their population and commercial advantages. All the interrogation sessions recorded for this study were conducted mainly in English and the subjects were adults (18years and above).

The process of gathering data for this study involved the use of research instrument such as tape-recording, interview and personal observation. Having sought and secured from the Area Commander of the towns involved, thirty-five interrogations of suspect sessions were witnessed and recorded by the researcher. Unstructured oral post-recording interview was used in few instances to clarify observed extra hyphen-linguistic cues during the interrogation sessions. The data gathered for this research work were transcribed and analysed using Gibbons (2008) Forensic Questioning model. In analysing the data, items were scored on the basis of frequency distribution and simple percentages.

The theoretical framework for this study is supported with Gibbons' (2008) forensic questioning model. This model is especially good for the analysis of institutional dyadic discourse of unequal participants. It is essentially good for police-suspect discourse because observation of the data gathered for this work has revealed that the greatest linguistic tool or weapon the police employed in establishing their institutional authority over suspects is question. In support of this, Stygall (1994) asserts that questions are a powerful tool the police interrogators use to control the flow of discourse, requesting particular information in a certain fashion, presenting the story in the order they impose, which does not necessarily follow the temporal succession of the actual events.

Gibbons (2008) postulates some questioning forms which are identified, analysed and discussed for this present study. They are (i) Declarative questions, (ii) Choice questions (iii)Wh-questions, (iv) Projected questions, and (v) Special formulas. According to Gibbons (2008), in police-suspect discourse, only one party is normally expected to ask questions and the other party is only allowed to respond and normally must respond.

Declarative Questions: These are questions loaded or embedded with the questioners' views, positions, ideas and propositions, aimed at indicting or convincing the respondent. According to Gibbons (2008), they are very powerful questions because they contain the proposition of the questioner. As can be inferred from above discussions, declarative questions have presuppositions and all questions posed in natural language will contain words or phrases that have emotive connotations, both positive and negative. According to Watson (2003, p.1791), the suggestiveness of a declarative question can have subtle effects on the respondent who is a witness. What may occur is that the suggestive terms in the question can result in the interrogator's views being incorporated into the memory of that witness.

Choice Questions: These are otherwise known as polar or Yes/No questions. They are questions that require the respondent to oscillate between two options of yes or no. The police make use of this type of question in police-suspect discourse to limit the choice of response of suspects. Such questions are also used by the police to prevent suspects from deviating from the subject of discourse. According to Gibbons (2008), these choice questions license in the response only information provided by the police interrogator.

WH-questions: These questions whether restricted or non-restricted are questions usually posed by the police for specific facts and information. They are introduced by WH-words such as where, who, when, why, how and what. This type of question is the one that is mostly employed by police officers in the course of their interaction with suspects.

Projected Questions: According to Gibbons (2008), questions in police interrogation usually contain verbal projection (reported speech). In these kinds of questions, the propositions of the police interrogator are usually embedded in them thereby placing high levels of pressure for agreement on the suspect. In a verbal projection, like 'You say that he killed the woman', there is an assumption that the speaker is committed to the truth of the core proposition (He killed the woman) rendering it very difficult to deny without branding oneself a liar. Therefore, if the person answers 'No' this denial is primarily a denial of saying this, but does not deny that he killed the woman (although the denial may affect this core proposition if there is no other evidence for the fact). The core information (He killed the woman) is to some degree presupposed or embedded.

Special Formulas: One characteristics of police interrogation is that there are occasions when police interrogators specifically mark the fact that the information is their version of events, not that of suspect, them challenge the suspect to agree. This is done by the use of legal formulas, the most common of which is "I put it to you that"." This phrase is not exclusively part of police domain and may be more frequently and more effectively used in courtroom discourse (e. g. cross examination). It is nonetheless a phrase which is unlikely to turn up in general conversation but which does appear with some frequency in police interrogation (Gibbons 2008).

\section{RESULTS AND DISCUSSION}

Overwhelmingly, the pattern in police interrogation is for the police to ask questions and for suspect to answer them. The fact that police-interrogator's role is essentially information seeking and the suspect's role is information giving, places control over topic navigation management in the interrogator's hands. Questions are initiating moves, answers are responding moves. 
TABLE 1

FREQUENCY Distribution OF THE QUESTIONING Forms In THE POLICE-SUSPECT DisCOURSE

\begin{tabular}{|l|l|l|l|}
\hline S/N & Questioning Forms & Frequency & Percentage \\
\hline 1. & Declarative & 25 & 28.4 \\
\hline 2. & Choice & 24 & 24 \\
\hline 3. & Projected & 19 & 21.6 \\
\hline 4. & WH- & 12 & 14.0 \\
\hline 5. & Special Formulas & 8 & 12 \\
\hline & Total & 88 & 100 \\
\hline
\end{tabular}

The table above shows the distribution of the questioning forms identified in the discourse. It shows that Declaratives are the most frequently used questioning form with a frequency of $25(28.4 \%)$. Next to Declarative is Choice which has 24 occurrences (24\%). Projected has 19 appearances (21.6) while WH- accounts for 12 instances (14.0\%) and lastly Special Formulas which has the least frequency distribution of $8(12 \%)$.

\section{A. Declarative}

Declarative questions are questions embedded with questioner's propositions and ideas which aim to convince the listener. They are very powerful questions because they contain the proposition of the questioner. One glaring fact is that this is a question that has the highest distribution of $28.4 \%$. This is hardly surprising however, since the aim of the Investigating Police Officer is to impose his proposition and his own version of reality on to the suspect so that he can confess his guilt. This is why the Investigating Police Officers in my data are always using declarative questions to project their propositions forward. This reveals the power that the police have over the suspect stemming from the type of questions they ask. For example:

1. IPO : I say you were parading yourself behind the house of Mr. Adekunle where It was alleged that thieves came there and they broke into the house and took away his properties. You were seen behind the house yesterday.

SUS : I did not go behind the house yesterday. 1 was passing to the second Street.

In example I above, the interrogator makes it clear that he is providing his own version of events by saying "I say" and is making a bald statement of his version "that the suspect was seen behind the house of the theft yesterday "for the suspect's agreement. Although the suspect initially denies this but he later confesses that he was just passing through that street to the second street.

2. IPO : Yesterday, it was discovered that you evacuated all your properties from your house through a lady?

SUS : That lady, let me say that she is my wife.

3. IPO : It was learnt that you carried those stuff in a Ghana-must-go bag so that another person may not discover the content of the bag

SUS: My landlord, everybody in my house knows that I took my food, my rice, my garri.

This type of question may sometimes have a rising question intonation, making it more questions-like as in examples 2 and 3 above. In the two examples above, the interrogator is also providing his own propositions and ideas wishing to convince the suspect. In police interrogation, this type is called a question, yet, it looks much more like an accusationone that the suspect is obliged to respond to by the rules of procedure.

\section{B. Choice Questions}

These are Yes/No form and alternative questions. Both of them are called choice questions because they both require choice for response. They have high frequency in the distribution table $24 \%$. This reason for this is that the IPO always wants to coerce and convince the suspects to their own idea. Hence, they are used maximally. They are powerful, coercive and controlling, because they limit the choice of the suspects' answer to a choice. Yes/No questions and alternative questions also contain propositions that the suspects are expected to pick from. For example:

4. IPO : Did you carry those items sealed in a Ghana-must-go bag?

SUS : Yes sir.

5. IPO: You mean the customs permitted you to buy those goods and bring them to Nigeria for sale as you had obtained all the custom papers.

SUS : Yes.

6. I.P.O : Do you know anything about that vehicle?

SUS: No. I don't know

7. I PO: Did you fight the policemen at the checkpoint in the course of demanding your paper?

SUS : No.

In each of the examples above, we can see how the IPO uses the questioning form to direct the interlocution in each case. The IPO's utterances determine as well as limit the contribution of the suspect. Examples 4-7 above already contain the propositions of the police interrogator and the suspect is just expected to pick between 'Yes' or 'No. In 
essence, of all the options available to the suspect to choose from in response, he cannot go beyond those given in the questions. This is where power lies. The questions have restricted the suspect's response to the options embedded in the questions given above. These choice questions license in the response only information provided by the interrogator.

\section{Restricted WH-questions}

This requests only specific information and facts. They are introduced by where, who, whom, when and which. They are more powerful that their non-restricted counterparts because they just require specific facts. For example, where requests place, which requests type, while when requests time or period and who/whom demands person or people, for example.

8. IPO : On $17^{\text {th }}$ October 2011 between, the hours of 8.30 am and $2 \mathrm{pm}$. where were you'?

SUS : I was in this Ondo. I was inside the school.

In example 8 , the $1 \mathrm{PO}$ wants to know between the specific time of $8.30 \mathrm{am}$ and $2 \mathrm{pm}$ where the suspect was and he replied that he was in Ondo, specifically, in the school. Consider this also:

9. I.P.O.: Who said so?

SUS: Alfa

Similarly in example 9, the suspect gives the name of the person that the IPO asked.

10. IPO: It is alright. When precisely did your family contributed the money for you after the death of your father?

SUS: On May $15^{\text {th }}, 2011$.

In example 10 also, the suspect gives an account of the timing of events when asked 'when' question.

\section{Non-restricted WH-questions}

This requires vivid, clear, informative and narrative details. It enables the suspect to supply more information about circumstances and motives, with this type of question, the interrogator simply names a topic, and then asks the suspect to tell what he knows about it. Examples of this type of question are what, how and why. For example;

11. IPO : Alright. Yesterday, why the police did stopped and brought you to the station for being in possession of the product.

SUS : They stopped me and said I should park and they asked my driver to park. Then they asked me what did I carry? I told them it is apple and I showed them my custom paper. So the police gave it to another man that was not in uniform. That one said we should follow them to the station.

12. IPO : You said you deal in apple business. And we know that apple is a foreign Product, how did you come about it'?

SUS : I went to Cotonou, as I got to Seme, I collected custom duties so that I will be coming with my goods.

In example 11 above, the 'why' question is answered with all and only the required information in the manner that he was brought to the police station. Similarly in example 12, the 'how' question receives similar response.

\section{E. Projection Questions}

These questions contain verbal projections. They also have high frequency on the distribution table 21.6\%. Projected questions are very powerful questions an IPO could ask. This is because they are very challenging, combating, controlling, powerful and coercive Let us consider some examples where this resource is used:

13. IPO: You said because of the sudden nature of the project, that was why you did not keep your money in the bank. Don't you think that project is not something sudden?

SUS : That money I said----- I said, you are throwing a lot of question to me. It is not surprising if $I$ have $\mathfrak{£ 1 0 0 , 0 0 0}$ in my own house. I am not too small to hold that money because I know my age

The question in example 13 presupposes that the suspect has recounted the reason why he did not keep his money in the bank which is very difficult to deny. As a matter of fact, the suspect did not deny but give another answer which is not related to the question.

14. IPO: According to you, you said you carried rice, beans and garri, in a bag and sealed it. Don't you think it will be difficult for the other people to know what was inside?

SUS: I will be very difficult.

In example 14, the basic from of the question is 'Don't you think it will be difficult for the other people to know what was inside". Once more, the projection "According to you, you said..." Makes it hard to deny and the suspect readily agrees with it. This acutely shows the power that police has over the suspect.

\section{F. Special Formulas}


Wherever they are used, they always issue challenges to the suspect. Although special formulas have the lowest frequency distribution, $12 \%$, they are by no means least coercive. Instances of utterances with special formulas in police-suspect interrogation analysed in this study further reveal that the IPO who is the dominant speaker, holds higher power and authority than the suspect. Special formulas therefore are means of manifesting the asymmetrical power relationship between the police and the suspect.

15. IPO: I put it to you that you are the person who stole those properties. That is what you will be saying after committing the offence?

SUS: Master, I am not the person who does this deed. I don't know anything about the theft.

16. IPO: I put it to you that you are a blatant liar?

SUS: I did not tell lies.

In these examples, the police interrogator used this set piece phrase as a last resort since other questions asked to establish that 'the suspect is the person responsible for the theft' had failed. But not surprisingly, since the suspect is a non-complaint person, this use of special formulas failed to achieve its objective of extracting an admission.

\section{CONCLUSION}

From the discussion above, we have seen that assault, abduction, affray and robbery were the common themes in Police-Suspect Discourse. Also, in Police-Suspect Discourse there are such questions as declarative, choice, restricted and non-restricted WH-questions, special formulas and projected questions. We have also seen that interrogation is a type of exchange in which the suspect is restricted in his power to control. The police interrogator controls and dominates this exchange. Suspect gives information and his role consists of simply giving answer to questions posed by the police interrogator. The suspect has little to say in what direction the exchange will take, and what questions are used. His role is to just answer questions posed to him by the police interrogator. We have equally seen how question forms are used by the police interrogator to obtain confession from the suspect. This is because of the power the police interrogator is having over suspect. There is asymmetrical relationship between the police interrogator and the suspect. The forms of these questions limit the scope for response in a range of ways, in an attempt to control the information provided by the suspect.

\section{REFERENCES}

[1] Adegbite, M. (2013). Politeness Strategies in Police-Suspect Discourse An unpublished M.A Thesis in the Department of English, Obafemi Awolowo University, Ile-Ife. .

[2] Ajayi, T. (2016). (Im)Politeness Strategies and Power Abuse in Police-Suspect Interaction in Ibadan, Nigeria. An unpublished PhD Thesis in the Department of Linguistics and African Languages, University of Ibadan, Ibadan.

[3] Dillon, J. T. (1990). The Practice Questioning. London: Routledge.

[4] Farinde, R. O. (2008) Forensic Linguistics: An Introduction to the Study of Language and the Law. Ago Iwoye: Olabisi Onabanjo University Press.

[5] Farinde, R. O. (2010). Discourse Acts in Police-Accused in Police-Accused Interrogation. In Language, Literature and Discourse: A Festschrift in Honour of Professor A.L.Oyeleye. Muenchen Germany: LINCOM GmbH. Pp 249-266.

[6] Fishman, P. M. (1983). Interaction: The Work Women Do. In Thorne B. [eds] et al Language, Gender and Society. Cambridge: Newbury House.

[7] Gibbons, J. P. (2008). Questioning in Common Law Criminal Courts. In Gibbons, J. and Turell, M. T [edsj Dimensions of Forensic Linguistics. Boston: John Benjamin's Publishing company Pp 115-130.

[8] Goodwin, M. H. (1990). He said-she said-Talk as social Organization among Black Children. Bloomington: Indiana University press.

[9] Goody, E. (1978). Towards a Theory of Questions in E. Goody [ed.] Questions and Politeness. Cambridge: Cambridge University Press.

[10] Hall, P. (2008). Police speak. In Gibbons, J. And Turell, M. T. [eds] Dimension of Forensic Linguistics. Boston: John Benjamin's Publishing Company. Pp 67-94.

[11] Hill, M. D. (2003). Identifying the source of Critical Details in Confessions. Forensic Linguistics. 10 (1) 23-43

[12] Leo, R. (1996). Inside the Interrogation Room. Journal of Criminal Law and Criminology 86 (2) Pp 266-303.

[13] Levy, E. O. (1999). Examination of Witness in Criminal cases $4^{\text {th }}$ ed Carswell; Scarborough, ON.

[14] Luchjenbroers, J. (1997). In Your Own Words. Questions and Answers in a Supreme Court Trial. Journal of Pragmatics 27; 477-503.

[15] Stygall, G. (1997). Trial Languages Differential discourse Processing and Discursive formation. Amsterdam and Philadelphia: John Benjamin's Publishing Company.

[16] Underwager, R. And Wakefield, H. (1992). False Confessions and Police Deception. American Journal of Forensic Psychology, 10 [3], 49-66.

[17] Walker, A. G. (1987). Linguistic Manipulation, Power and the legal setting. In L. Kedar [ed] Power through Discourse. Norwood, NJ Ablex Pp 57-79

[18] Walton, D. (2003). The Interrogation as a Type of Dialogue. Journal of Pragmatics, 35. 1771-1802. 
Raifu Olanrewaju FARINDE attended Adeyemi College of Education, Ondo, Nigeria, for his Bachelor's Degree in English Education. He obtained his M.A in English Language from the University of Ibadan, Nigeria. He also bagged his PhD in Linguistics and English Language from the University of Wales, Bangor, United Kingdom now Bangor University, Bangor, United Kingdom. At present, he is a Senior Lecturer and the Head of the Department of English and Literary studies, Federal University Oye-Ekiti, Nigeria. He has published in both national and international journals. Among his published works includes Forensic Linguistics: An introduction to the Study of Language and the Law Allemagne, Germany: LIMCOM GMBH, 2009. He also co-authored with Dr. Ojo J.O. Introduction to Sociolinguistics Ondo, Nigeria: Lektay Publishers, 2005, and The Grammatical Structures of English: An Illustrative Approach, Pat Ade Publishers 2000. Furthermore, he co-authored with Dr. Yemi Ogunsiji Analytical Linguistics AgoIwoye, Nigeria: Olabisi Onabanjo University Press. 2010. His research interests include Pragmatics, Forensic Linguistics, Discourse Analysis, Sociolinguistics and Systemic Functional Grammar. He is a recipient of Ford Foundation International Fellowship for PhD organized by the Institute of International Education (IIE) New York between 2003 and 2006. Among his awards, honours and distinctions are Certificate of Achievement, UK, 2005, Certificate of Completion, 2004, and Certificate of Recognition, 2013.

Wasiu Ademola OYEDOKUN-ALLI is a Senior Lecturer in English and Linguistics and currently the Acting Director, General Studies Unit of Federal University Oye-Ekiti. He was also the pioneer Head, Department of English, Federal University Oye-Ekiti, Nigeria. He holds a doctorate degree from the Ahmadu Bello University Zaria in the year 2010. He also studied Law at the University of Ibadan.2002-2007. He was called to the Nigerian Bar in the year 2008, having passed the Bar Finals the same year. He was at different times, Adjunct Senior Lecturer at Afe Babalola University, Ado-Ekiti, Nigeria and Kings University, Ode-Omu, Nigeria. Dr. (Barr.) Oyedokun-Alli has authored many textbooks in English Linguistics and Communication Skills and has also published in many high-impact journals. His Research interests are in Sociolinguistics, Applied Linguistics, Discourse Analysis and Forensic Linguistics. He is a Member, Linguistic Association of Nigeria; Member, Reading Association of Nigeria; Member Association for the Promotion of Nigerian Languages and Cultures; Member Association for the promotion of Development Studies; Member, Nigerian Bar Association, among others.

Obinna Iroegbu $(\mathrm{PhD})$ is a Lecturer in the Department of English and Literary Studies, Federal University, Oye-Ekiti, Ekiti State, Nigeria. He holds a First Degree in English Studies from the University of Port Harcourt. His Master's and PhD, obtained from Ekiti State University and University of Port Harcourt, respectively, were on J.P. Clark's poetry. He has published a number of journal articles on Clark's poetry and other issues in language and literature. Dr Iroegbu's main research interest is in the language of literature (Stylistics). He also teaches courses in English Morphology and Syntax as well as Pragmatics and Discourse Analysis. 